\title{
Imperforate anus with rectopenile fistula: a case report and systematic review of the literature
}

\author{
Gang Yang ${ }^{1}$, Yingli Wang ${ }^{2}$ and Xiaoping Jiang ${ }^{1 *}$
}

\begin{abstract}
Background: Although anorectal malformations (ARMs) are frequently encountered, rare variants difficult to classify have been reported.

Methods: This study describes a patient with ARM and rectopenile fistula. The literature was reviewed systematically to assess the anatomical characteristics, clinical presentations and operations of this rare type of ARM.

Results: Eight patients were reported in the six included articles. In three patients, the fistula extended from the rectum to the anterior urethra without communication with the skin. In one patient, the fistula, located deep in corpus spongiosum, opened to the ventral aspect of the penis without communication with the urethra. In the remaining four patients, the fistula extended from the rectum to the cutaneous orifice in the ventral aspect of penis, with communication or a short common channel with the urethra.

Conclusions: Imperforate anus with fistula extending into the penis is a rare variant of anorectal malformation. Unawareness of this lesion resulted in a delay of correct diagnosis and appropriate management. A thorough examination, including colonourethrography and fistulography, should be performed in all patients with a fistula opening in the ventral aspect of the penis.
\end{abstract}

Keywords: Anorectal malformation, Rectopenile fistula, Systematic review

\section{Background}

Anorectal malformations (ARMs) are frequently encountered anomalies of diverse types. Most types of ARMs can be determined by a thorough perineal inspection or colostogram. Some rare variants, however, may be difficult to classify. This report describes a rare form of ARM with a fistula opening in the ventral aspect of the penis and communicating with the urethra. The literature was reviewed systematically to assess the anatomical characteristics, clinical presentations and operations of this rare type of ARM. Understanding of this lesion is critical for early diagnosis and appropriate treatment.

\footnotetext{
*Correspondence: emailtoyg@163.com

'Department of Pediatric Surgery, West China Hospital, Sichuan University, Chengdu 610041, People's Republic of China

Full list of author information is available at the end of the article
}

\section{Case report}

A 4-h-old male newborn weighing 3,400 g was referred to our hospital with an imperforate anus. There was no orifice in the perineal region. A white median raphe cyst, $4 \mathrm{~mm}$ in diameter, was present on the ventral side of the penis. Auscultation of the heart and lungs was normal. The patient's family history was unremarkable. After 24 $\mathrm{h}$, the color of the middle raphe cyst turned dark green. The cyst was incised at bedside, and meconium passed from it. Insertion of a soft catheter showed a deep fistula running parallel to the urethra (Fig. 1a). Urination was normal, with no urine passed from the fistula. Urethrography and fistulography, performed 3 and 4 days after birth, respectively, showed a long fistula running parallel to the urethra from the rectal pouch to the penis (Fig. 1b). The distance between the rectal pouch and the anal dimple was $1 \mathrm{~cm}$. During urethrography, a small amount of contrast retrograde had flowed into the rectal pouch (Fig. 2a), suggesting a communication between 

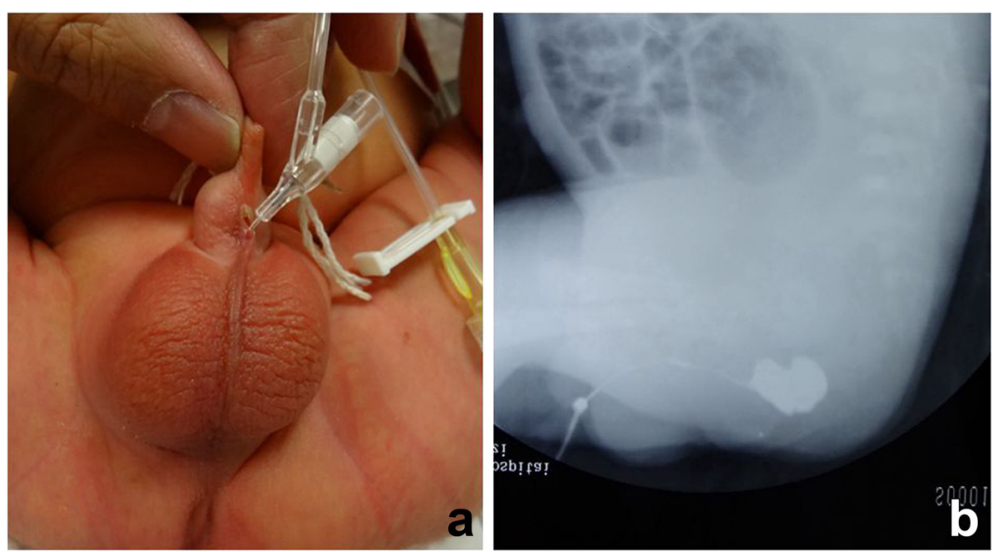

Fig. 1 a A catheter was inserted into the orifice of the fistula. b Fistulography showed the fistula and the end of the rectum

the fistula and the urethra. X-rays and ultrasound did not show any anomalies in the sacrum and spinal cord. No other anomalies could be identified.

One-stage limited posterior sagittal anorectoplasty (PSARP) was performed on the fourth day after birth. With the urethral catheter indwelling, the patient was placed in the prone position, and a sagittal incision was made. The posterior rectal wall was opened in the midline and extended distally, ending directly at the fistula, which was $2 \mathrm{~mm}$ in diameter. The dissection continued between the rectum and the urethra until the two structures were completely separated from each other. The distal end of the fistula was ligated to the remaining part of the corpus spongiosum penis (Fig. 2b). The muscles were repaired and anorectoplasty was performed. The urethral catheter was removed on the seventh postoperative day and there was no difficulty in urination. Patient recovery was uneventful and he was discharged on the eighth postoperative day. Follow-up for eight months has shown no evidence of secretion passing from the opening of penile fistula, and the patient has been doing well. Bowel control could not be evaluated owing to patient age.

\section{Methods}

The systematic review of patients with imperforated anus and rectopenile fistula adhered to PRISMA guidelines. PubMed and EMBASE (from January 1989) were systematically searched for relevant articles published in English through November, 2014, using as search terms: (anorectal malformation OR imperforate anus) AND (penis fistula). The titles and abstracts of all potential relevant articles were read to determine their relevance. Full articles were also scrutinized if the title and abstract were unclear. Reference lists of identified articles were screened for additional publications of interest.

Studies were included if they assessed patients with ARM having fistulas extending from the rectal pouch to
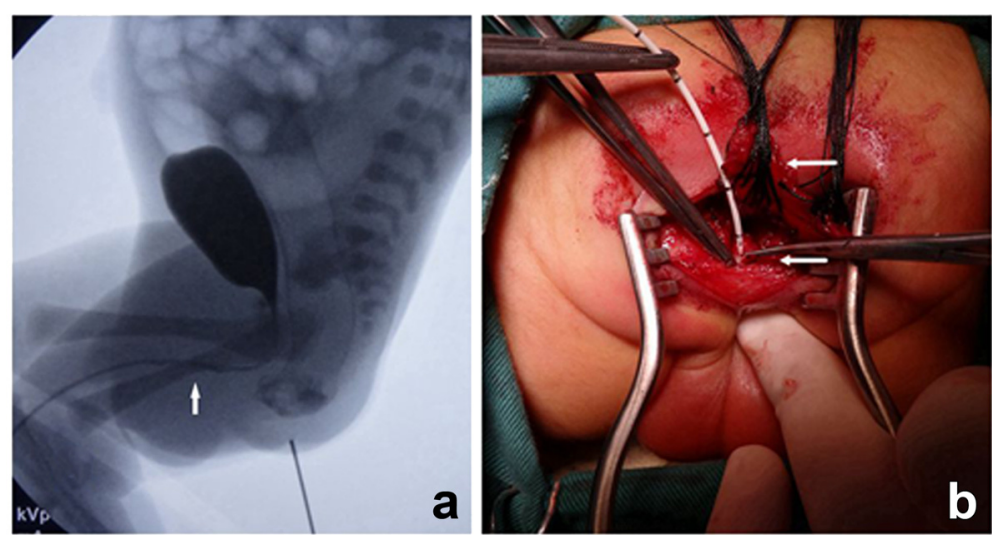

Fig. 2 a Urethrography showed the urethra and the bladder. A small amount of contrast appeared in the rectum. The location of fistula entering the urethra was displayed (arrow). b Limited PSARP was performed. The rectum had been divided (upper arrow) and a catheter was inserted to the fistula (lower arrow) 
the penis deep in the spongy urethra, with or without connections to the urethra. Studies were also included if they described treatment details and showed radiographic images. Only studies published in English were included. Review articles and editorials were excluded.

All identified articles were independently assessed by two authors. Detailed data regarding study design, patient characteristics, initial diagnoses, radiological diagnoses, symptoms, and treatment were extracted into an electronic data sheet in a standardized manner.

\section{Results}

Of the 52 papers identified by searching the databases, four met the study criteria and were included [1-4]. No reports were repetitive. Two additional articles were identified by manual searching $[5,6]$. The 48 papers excluded were review articles, irrelevant to the current study or published in a language other than English (Fig. 3). Table 1 shows the details of the included articles.

The six included articles described a total of eight patients. In all eight, the ends of the rectum were below the ischial line. In three patients, the fistulas extended from the rectum to the anterior urethra without communicating with the skin. In one patient, the fistula, located deep in the corpus spongiosum, opened to the ventral aspect of the penis without communicating with the urethra. In the other four patients, the fistulas extended from the rectum to the cutaneous orifices on the ventral aspect of the penis, communicating with or sharing a short common channel with the urethra. Each of the eight patients underwent two to four operations. Although having a low type of ARM, seven patients underwent colostomy owing to the puzzling courses of the fistulas. Anoplasty was completed by perineal operations in six patients, an anterior sagittal approach in one and a posterior sagittal approach in one. In two patients, the fistulas were not removed because they did not communicate with the urethra. Five of these eight patients had other anomalies, including congenital heart disease, bifid scrotum, solitary kidney, hypospadias, undescended testis and hydronephrosis.

\section{Discussion}

ARM with fistula deep in the spongy urethra, with or without communication with the urethra, is a rare anomaly [7]. The nine patients reported to date can be classified into three groups (Fig. 4). The first group consists of patients with an imperforate anus and a fistula running parallel to the urethra, extending from the

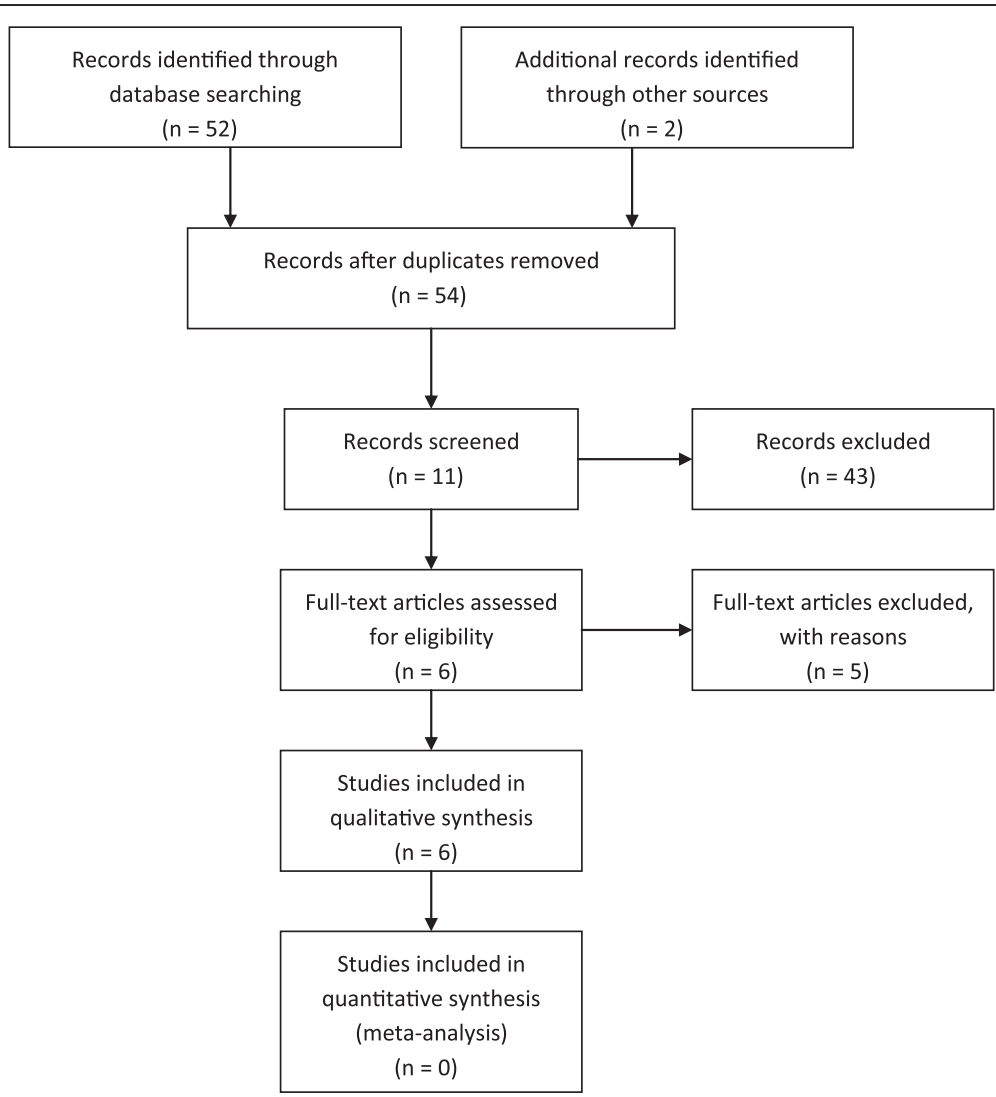

Fig. 3 PRISMA flow chart of literature search 
Table 1 Summary of included cases

\begin{tabular}{|c|c|c|c|c|c|c|c|c|}
\hline Authors & Year & $\begin{array}{l}\text { Age of } \\
\text { Diagnosis }\end{array}$ & Type of Fistula & $\begin{array}{l}\text { Level of rectum } \\
\text { (distance to skin) }\end{array}$ & Operation & Management of fistula & Associated anomalies & Complications \\
\hline Ohno et al. & 2008 & 6 months & $\begin{array}{l}\text { parallel to the urethra } \\
\text { from the rectal pouch } \\
\text { to the spongy urethra }\end{array}$ & $\begin{array}{l}\text { Below the ischium } \\
(1 \mathrm{~cm})\end{array}$ & $\begin{array}{l}\text { Transverse colostomy, } \\
\text { ASARP, colostomy } \\
\text { clousure }\end{array}$ & $\begin{array}{l}\text { Severed from the } \\
\text { rectum and ligated }\end{array}$ & Right aortic arch & $\begin{array}{l}\text { Vesicoureteral reflux, } \\
\text { constipation }\end{array}$ \\
\hline Kumar et al. & 2005 & 18 months & $\begin{array}{l}\text { between the anal canal } \\
\text { and the skin in the } \\
\text { peno-scrotal junction, } \\
\text { with a small portion of } \\
\text { common channel in the } \\
\text { penile urethra }\end{array}$ & & $\begin{array}{l}\text { Anoplasty, colostomy + } \\
\text { fistula excision }\end{array}$ & removed & & \\
\hline Shah et al. & 2003 & 9 months & $\begin{array}{l}\text { From the rectum to the } \\
\text { ventral aspect of the } \\
\text { penis, no communication } \\
\text { with urethra }\end{array}$ & low & $\begin{array}{l}\text { Transverse colostomy, } \\
\text { PSARP, colostomy closure }\end{array}$ & $\begin{array}{l}\text { Ligated, distal part } \\
\text { was kept undisturbed }\end{array}$ & Solitary kidney & \\
\hline \multirow[t]{2}{*}{ Currarino et al. } & 1994 & 9 months & $\begin{array}{l}\text { extending from rectum } \\
\text { to cutaneous orifice } \\
\text { near the penoscrotal } \\
\text { junction, with } \\
\text { communication with the } \\
\text { bulbar urethra }\end{array}$ & Below the ischial line & $\begin{array}{l}\text { Perineal anoplasty, descending } \\
\text { colostomy, fistula excision }\end{array}$ & & $\begin{array}{l}\text { Bifid scrotum, mild sacral } \\
\text { anomalies }\end{array}$ & Urinary tract infection \\
\hline & & 2 days & $\begin{array}{l}\text { A long rectocutaneous } \\
\text { fistula open on the } \\
\text { undersurface of the } \\
\text { penis, communicating } \\
\text { with the bulbar urethra }\end{array}$ & Below the ischial line & $\begin{array}{l}\text { Colostomy, sacroperineal } \\
\text { rectal pull-through with } \\
\text { ligation of rectal fistula, } \\
\text { colostomy closure, excision } \\
\text { of urethrocutaneous fistula }\end{array}$ & & Bifid scrotum & \\
\hline \multirow[t]{2}{*}{ Takamatsu et al. } & 1993 & 11 months & $\begin{array}{l}\text { Fistula between the } \\
\text { anorectum and anterior } \\
\text { urethra }\end{array}$ & below the I line & $\begin{array}{l}\text { Sigmoid colostomy, perineal } \\
\text { anoplasty and revision of } \\
\text { the fistula }\end{array}$ & & $\begin{array}{l}\text { Bifida scrotum, hypospadias, } \\
\text { right undescended testicle, } \\
\text { right hydronephrosis, } \\
\text { congenital heart disease }\end{array}$ & \\
\hline & & Unknown & $\begin{array}{l}\text { Fistula between the } \\
\text { anorectum and anterior } \\
\text { urethra }\end{array}$ & Below the I line & $\begin{array}{l}\text { Sigmoid colostomy, revision } \\
\text { of fistula and perineal } \\
\text { anoplasty }\end{array}$ & & & \\
\hline Asano et al. & 1983 & 3 months & $\begin{array}{l}\text { Fistula from rectum and } \\
\text { open in the ventral } \\
\text { surface of the penis, } \\
\text { communication with } \\
\text { urethra }\end{array}$ & Under the skin & $\begin{array}{l}\text { Cutback procedure, excision } \\
\text { of the fistula }\end{array}$ & & & \\
\hline
\end{tabular}



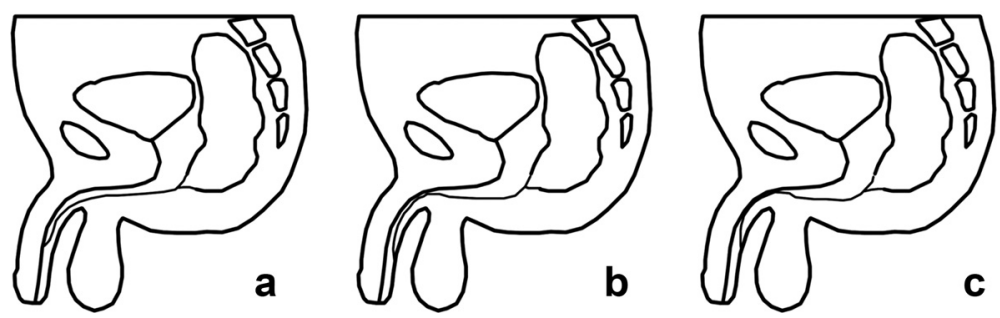

Fig. 4 Diagrams for the different type of malformations (a anopenile urethral fistula; $\mathbf{b}$ fistula extending in the corpus spongiosum and opening in the ventral aspect of the penis; c Fistula with a communication or a short common channel with the urethra)

rectal pouch to the anterior urethra, a condition defined as anopenile urethral fistula. The second group consists of patients with an imperforate anus and a fistula extending to the corpus spongiosum and opening in the ventral aspect of the penis. The third group consists of patients with an imperforate anus and a fistula passing distally within the corpus spongiosum and ending in the ventral aspect of the penis, with a communication or a short common channel with the urethra.

The embryology of these anomalies has not been determined. One study reported that this condition was a variant of anorectal malformation with a deep rectocutaneous fistula that may partially fuse with the urethra [6]. The patient described in this report could be classified into the third group. A filiform fistula must have been present between the rectal pouch and the urethra, because the contrast retrograde flowed into the rectal pouch during urethrography.

Determination of anatomy is important in the management of ARM. Thorough perineal inspection may provide important clues about the anatomical type [8]. Median raphe cysts usually occur in low-type anorectal malformations and suggest the location of the fistula [9]. In our patient, a probe tube was inserted into the fistula after incision of the median raphe cysts. A fistula was observed deep within the urethra cavernosum, excluding the possibility of a perineal fistula. Urethrography and fistulography with water soluble contrast radiography were important in delineating the fistula in all eight patients.

Anorectoplasty in patients with "low type" malformation can be completed through a perineal, anterior sagittal or limited posterior sagittal approach [10]. Bowel control was excellent in most reported cases. Diverting colostomy may be unnecessary, providing that the anatomical structure is understood and delineated before surgery. Colostomy, however, is prudent if there is any suspicion about the anatomy. Fistula management should be individualized, with no uniform recommendations made. The origin of the fistula from the rectum must be ligated. The distal part of the fistula may be kept undisturbed or removed based on its relationship with the urethra, the estimated risk of infection and the difficulty of the procedure.

\section{Conclusions}

Imperforate anus with the fistula extending into the corpus spongiosum is rare, but good prognosis can be achieved by appropriate treatment. However, lack of awareness of these lesions may delay a correct diagnosis, putting patients at risk of multiple operations. Therefore, patients with a fistula opening in the ventral aspect of the penis should be thoroughly examined, including by colonourethrography and fistulography, to clarify their anatomy before surgery.

\section{Consent}

Written informed consent was obtained from the patient's parents for publication of this Case report and any accompanying images. A copy of the written consent is available for review by the Editor-in-Chief of this journal.

\section{Ethical statement}

This study was approved by the Ethics Committee of West China Hospital.

\section{Availability of data and materials \\ Not applicable.}

Competing interest

The authors declare that they have no competing interest.

\section{Authors' contributions}

YG contributed to the drafting of the manuscript, acquisition of data and analyzing the data. WYL contributed to performing the database searching and evaluation of the included articles. JXP contributed to designing of the study, interpretation the data and final approval of the version to be published. All authors have read and approved the final manuscript.

\section{Acknowledgements}

The authors sincerely thank the patient and his parents for providing all of the clinical information.

\section{Author details}

1Department of Pediatric Surgery, West China Hospital, Sichuan University, Chengdu 610041, People's Republic of China. ${ }^{2}$ Department of Hematology, West China Hospital, Sichuan University, Chengdu 610041, People's Republic of China. 
Received: 11 January 2015 Accepted: 11 May 2016

Published online: 13 May 2016

\section{References}

1. Ohno K, Nakamura T, Azuma T, Yoshida T, Yamada H, Hayashi H, Masahata K. Anopenile urethral fistula. Pediatr Surg Int. 2008:24:487-9.

2. Kumar $\mathrm{V}$, Rao PL, Vepakomma D. Low anorectal malformation associated with 'ano-urethro-cutaneous' fistula. Pediatr Surg Int. 2005;21:829-30.

3. Shah AA, Shah AV. Imperforate anus with rectopenile fistula. Pediatr Surg Int. 2003;19:559-61.

4. Asano S, Kitatani H, Konuma K. A newborn with a covered anus complicated by two concomitant unique fistulas. Z Kinderchir. 1983;38:258-61.

5. Takamatsu H, Noguchi H, Tahara H, Kajiya H, Kaji T, Ikee T, Yoshioka T, Akiyama $\mathrm{H}$. Ano-urethral fistula, a special type of anomaly: report of two cases. Surg Today. 1993;23:1116-8.

6. Currarino G. Imperforate anus associated with a recto-bulbar-cutaneous fistula. J Pediatr Surg. 1994:29:102-5.

7. Endo M, Hayashi A, Ishihara M, Maie M, Nagasaki A, Nishi T, Saeki M. Analysis of 1,992 patients with anorectal malformations over the past two decades in Japan. Steering Committee of Japanese Study Group of Anorectal Anomalies. J Pediatr Surg. 1999;34:435-41.

8. Bischoff A, Levitt MA, Peña A. Update on the management of anorectal malformations. Pediatr Surg Int. 2013;29:899-904.

9. Soyer T, Karabulut AA, Boybeyi Ö, Günal YD. Scrotal pearl is not always a sign of anorectal malformation: median raphe cyst. Turk J Pediatr. 2013;55: 665-6.

10. Kuijper CF, Aronson DC. Anterior or posterior sagittal anorectoplasty without colostomy for low-type anorectal malformation: how to get a better outcome? J Pediatr Surg. 2010;45:1505-8.

\section{Submit your next manuscript to BioMed Central} and we will help you at every step:

- We accept pre-submission inquiries

- Our selector tool helps you to find the most relevant journal

- We provide round the clock customer support

- Convenient online submission

- Thorough peer review

- Inclusion in PubMed and all major indexing services

- Maximum visibility for your research

Submit your manuscript at www.biomedcentral.com/submit 